\title{
Article
}

\section{The Role of Carbon Nanotube Pretreatments in the Adsorption of Benzoic Acid}

\author{
Pierantonio De Luca ${ }^{1, * \mathbb{C}}$, Carlo Siciliano ${ }^{2} \mathbb{C}$, Anastasia Macario ${ }^{3}\left(\mathbb{C}\right.$ ) and Jànos B. Nagy ${ }^{1}$ \\ 1 Department of Mechanical, Energy and Management Engineering, University of Calabria, \\ I-87036 Arcavacata di Rende, Italy; janos.bnagy1@gmail.com \\ 2 Department of Pharmacy, Health and Nutritional Sciences, University of Calabria, \\ I-87036 Arcavacata di Rende, Italy; carlo.siciliano@unical.it \\ 3 Department of Environmental Engineering, University of Calabria, I-87036 Arcavacata di Rende, Italy; \\ anastasia.macario@unical.it \\ * Correspondence: pierantonio.deluca@unical.it; Tel.: +39-0984-496757
}

Citation: De Luca, P.; Siciliano, C.; Macario, A.; Nagy, J.B. The Role of Carbon Nanotube Pretreatments in the Adsorption of Benzoic Acid. Materials 2021, 14, 2118. https:// doi.org/10.3390/ma14092118

Academic Editor: Weon Ho Shin

Received: 1 April 2021

Accepted: 20 April 2021

Published: 22 April 2021

Publisher's Note: MDPI stays neutral with regard to jurisdictional claims in published maps and institutional affiliations.

Copyright: (c) 2021 by the authors. Licensee MDPI, Basel, Switzerland. This article is an open access article distributed under the terms and conditions of the Creative Commons Attribution (CC BY) license (https:/ / creativecommons.org/licenses/by/ $4.0 /)$.
Abstract: Four different types of multi-walled carbon nanotubes (MWCNTs) were used and compared for the treatment of benzoic acid contaminated water. The types of nanotubes used were: (1) non-purified $\left(\mathrm{CNTs}^{\mathrm{UP}}\right)$, as made; (2) purified $\left(\mathrm{CNTs}^{\mathrm{P}}\right)$, not containing the catalyst; (3) oxidized $\left(\mathrm{CNTs}^{\mathrm{OX}}\right)$, characterized by the presence of groups such as, $-\mathrm{COOH}$; $(4)$ calcined $\left(\mathrm{CNTs}^{900}\right)$, with elimination of interactions between nanotubes. In addition, activated carbon was also used to allow for later comparison. The adsorption tests were conducted on an aqueous solution of benzoic acid at concentration of $20 \mathrm{mg} / \mathrm{L}$, as a model of carboxylated aromatic compounds. After the adsorption tests, the residual benzoic acid concentrations were measured by UV-visible spectrometry, while the carbon nanotubes were characterized by TG and DTA thermal analyses and electron microscopy (SEM). The results show that the type of nanotubes thermally treated at $900{ }^{\circ} \mathrm{C}$ has the best performances in terms of adsorption rate and amounts of collected acid, even if compared with the performance of activated carbons.

Keywords: benzoic acid; carbon nanotubes; functionalization; active carbons; adsorption

\section{Introduction}

Carbon nanotubes are materials that are increasingly known and studied thanks to their peculiar properties and their high versatility that make them effective in many sectors. They can be described as coiled sheets of graphene that form nanometer-sized tubular structures [1-4]. Carbon nanotubes can be advantageously used above all in the treatment of water contaminated by pollutants, thanks to their extraordinary adsorbing properties [5-9]. They often exhibit competitive adsorbing properties with the most common adsorbing materials, such as natural materials $[10,11]$, chitosans [12,13], activated carbon $[14,15]$ and microporous materials $[16,17]$. Lately, many studies report the advantageous use of carbon nanotubes in the treatment of water contaminated by organic pollutants, such as hydrocarbons [18-21], dyes [22-26] and heavy metals [27-29].

In literature, many studies are reported on the removal of benzoic acid both because it can be considered as representative of aromatic organic pollutants and because it is a potentially dangerous pollutant. Benzoic acid is an important chemical preservative used mainly in the food industry. Although many countries have banned and limited its use as a food additive, it is often present in industrial wastewater, capable of causing risks to the environment and human health [30]. The main sources of benzoic acid in the environment are coal refining plants, paper production plants, and the agricultural sector [31]. Many studies have highlighted the effects of benzoic acid and its derivatives on the quality of the water and on the health of its inhabitants. Furthermore, the benzoic acid in the environment can undergo transformations, for example, into halogenated or hydroxylated 
forms, which are often more dangerous $[32,33]$. The treatment of waters contaminated by benzoic acid is attracting a lot of interest in researchers who are increasingly active in researching new and more effective methods of removal. In recent years, much research has been aimed at studying the adsorption of benzoic acid with carbon nanotubes. In 2009, Kotel et al. showed that both chemical and thermal pretreatments on carbon nanotubes can significantly improve the ability to adsorb benzoic acid [34]. In 2018, Dai et al. reported a study on the adsorption of benzoic acid through new microporous nano composites synthesized on multi-walled carbon nanotubes, functionalized with different methods. These new nano composites showed excellent adsorbent performances and potential applications for the removal from polluting waters of dangerous organic materials such as benzoic acid [35].

Recently, some researchers have shown that single-walled nanotubes synthesized by the thermal decomposition of ferrocene $\left(\mathrm{Fe}\left(\mathrm{C}_{2} \mathrm{H}_{5}\right)_{2}\right)$ are able to efficiently remove benzoic acid with higher efficiencies than multi-walled nanotubes. Through simulation studies of molecular dynamics, they have shown that the high efficiency of single-walled carbon nanotubes is attributable to sites with high bonding energy [36].

Other studies report the use of SWNT functionalized with carboxylic groups, where the low degree of oxygenation of the surface of the carbon nanotubes leads to a greater adsorption of benzoic acid [37].

The aim of this work was to determine the best adsorption performance of purified, non-purified, oxidized, and calcined MWCNTs. The results are compared with the adsorption properties of activated carbon, used as a reference. Specifically, different types of carbon nanotubes were synthesized, with different chemical-physical characteristics, and tested for the removal of benzoic acid in aqueous solutions.

The post-process analyses were performed by UV spectrophotometry for the residual concentration in solution and thermogravimetric analysis to confirm the presence of benzoic acid on the walls of the carbon nanotubes. Finally, the different samples after the adsorption tests were observed with scanning electron microscopy (SEM).

\section{Materials and Methods}

\subsection{Materials}

The aqueous solution was prepared using commercial benzoic acid (Carlo Erba, $99.9 \%$ weight, Milan, Italy) with a concentration $20 \mathrm{mg} / \mathrm{L}$ equal to $0.164 \mathrm{nM}$, as representative of the waste waters [38]. Activated carbon was purchased (Merck, Darmstadt, Germany). Unpurified, purified and oxidized carbon nanotubes were synthesized as already reported in previous studies [19,39].

Carbon nanotubes calcined at $900{ }^{\circ} \mathrm{C}$ were prepared during this research. In particular, the pretreatments of the nanotubes are reported below.

In the previous work [39], the purified carbon nanotubes, precursors of non-purified, oxidized and calcined carbon nanotubes, were subjected to $\mathrm{N}_{2}$ adsorption, showing an $\mathrm{N}_{2}$ capacity equal to $0.85 \mathrm{nmol} / \mathrm{g}$, BET surface $\mathrm{m}^{2} / \mathrm{g}$ equal to $108.78 \mathrm{~m}^{2} / \mathrm{g}$, an average pore width equal to $103.70 \AA$ and $4-5$ concentric layers. Figure 1 displays the structure of benzoic acid.

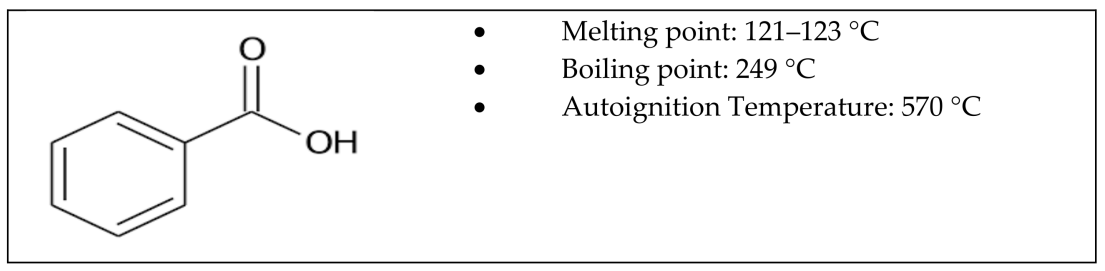

Figure 1. Structure and thermal characteristics of benzoic acid. 


\subsubsection{Preparation of Unpurified Carbon Nanotubes (CNTs ${ }^{\mathrm{UP}}$ )}

The synthetic method used for the production of $\mathrm{CNTs}^{\mathrm{UP}}$ was the catalytic chemical vapor deposition (CCVD) method. The supported catalyst used was a Co-Fe on NaY (UOP Y-54 DR PWD) zeolite. The metallic percentage was of 5\% wt for each. The catalysts were prepared by impregnation method on the powdered zeolitic phase. The source of carbon was ethylene using $\mathrm{N}_{2}$ as carrier gas. The synthesis temperature was $700{ }^{\circ} \mathrm{C}$ with a reaction time of $20 \mathrm{~min}$. The carbon deposit (CD) of this reaction was of $1447 \%$. These types of carbon nanotubes contained traces of the catalyst (Figure 2a).

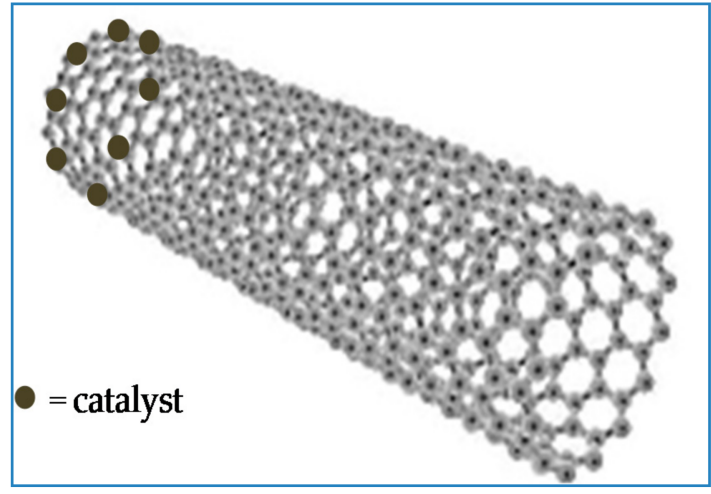

(a)

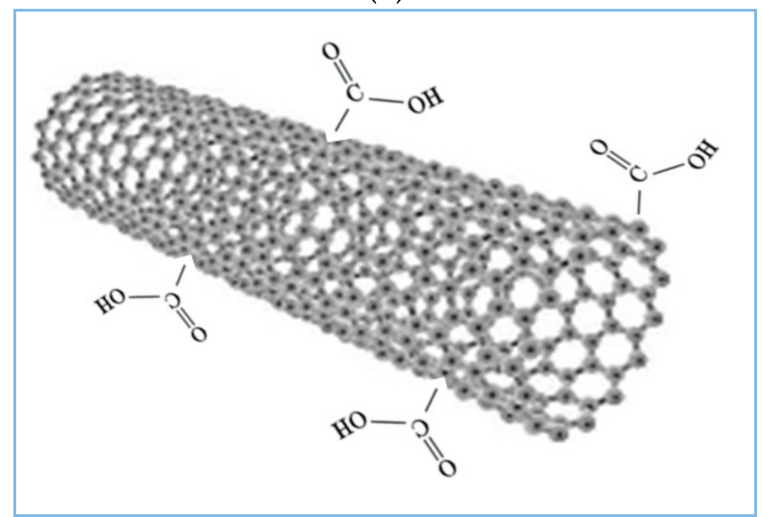

(c)

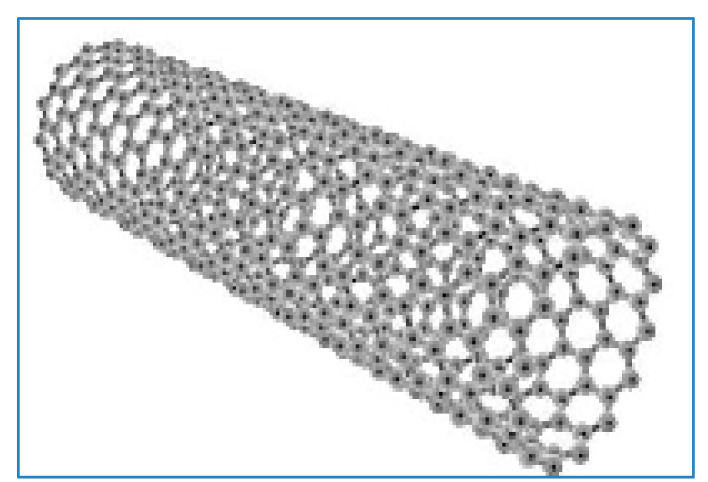

(b)

Figure 2. Schematic representation of the main characteristics of the different types of nanotubes used: (a) with the presence of catalyst; (b) without catalyst and functional groups; (c) without the presence of catalyst and with carboxyl groups.

\subsubsection{Preparation of Purified Carbon Nanotubes $\left(\mathrm{CNTs}^{\mathrm{P}}\right)$}

The purified carbon nanotubes were prepared by treatment of the previously prepared unpurified carbon nanotubes (CNTs ${ }^{\mathrm{UP}}$ ) dissolving the zeolitic support in HF (Sigma-Aldrich, $40 \% \mathrm{wt}$ ) and avoiding the presence of metallic oxides with several steps of washing. The total process time was 5 days. This treatment allowed the removal of the catalyst (Figure 2b).

\subsubsection{Preparation of Oxidized Carbon Nanotube $\left(\mathrm{CNTs}^{\mathrm{OX}}\right)$}

The oxidized carbon nanotubes $\left(\mathrm{CNTs}^{\mathrm{OX}}\right)$ were prepared by purified carbon nanotubes $\left(\mathrm{CNTs}^{\mathrm{P}}\right.$ ) using a mixture of $\mathrm{HNO}_{3}$ (Sigma-Aldrich, St. Louis, MO, USA, 65\% wt) and $\mathrm{H}_{2} \mathrm{SO}_{4}$ (Sigma-Aldrich, 99\% wt) with a ratio $\mathrm{HNO}_{3} / \mathrm{H}_{2} \mathrm{SO}_{4}$ of 0.6 in for $24 \mathrm{~h}$. The carbon nanotubes thus pretreated contained carboxylic groups on the surface and were catalystfree (Figure 2c). Many studies reported in the literature have shown that these carbon nanotube oxidation treatments lead to functionalization with carboxylic groups [40]. 


\subsubsection{Preparation of Calcined Nanotubes $\left(\mathrm{CNTs}^{900}\right)$}

To prepare calcined nanotubes, the purified nanotubes were treated at $900{ }^{\circ} \mathrm{C}$ for $4 \mathrm{~h}$, using $\mathrm{N}_{2}$ only. These types of carbon nanotubes were completely free from traces of catalyst and carboxylic groups (Figure 2b).

\subsection{Adsorption Tests}

The adsorption tests were carried out by introducing $0.05 \mathrm{~g}$ of the selected adsorbent material into a flask and to which $100 \mathrm{~mL}$ of a benzoic acid solution with concentration $20 \mathrm{mg} / \mathrm{L}$ was added. The whole system, at room temperature, was subjected to magnetic stirring. At different pre-selected adsorption times, equal to 10, 30, 90, $200 \mathrm{~min}$, the tests were stopped and the solution separated from the solid phase by filtration. The adsorption time was stopped at $200 \mathrm{~min}$ because we wanted to study a feasible and practical time interval for an adsorption treatment. The two phases, solid and liquid, were recovered and subsequently subjected to characterization.

\subsection{Characterization}

The concentrations of benzoic acid in aqueous solutions were detected by spectrophotometer UV (UV-3100PC, Shimadzu, Kyoto, Japan) in the range 300-1100 nm.

The adsorption measurements were repeated three times and the values were averaged. The thermo-analytical measurements were performed on the automatic TG/DTA instrument (Shimadzu-60, Shimadzu, Kyoto, Japan) under air flow $(50 \mathrm{cc} / \mathrm{min}$ with heating rate of $\left.10{ }^{\circ} \mathrm{C} \mathrm{min}-1\right)$. The morphology of the products were examined on a scanning electron microscope (FEI, Hillsboro, OR, USA). The sample preparation relied on the classical method. About $10 \mathrm{mg}$ of CNTs was suspended in $3 \mathrm{~mL}$ ethanol, and the suspension was then deposited on a carbonated $\mathrm{Cu}$ - $\mathrm{Rh}$ grid. The $\mathrm{pH}$ values were measured by portable pH-meter (Bicasa, Monza Brianza, Italy).

\section{Results}

\subsection{Characterization of Carbon Nanotubes}

Non-purified $\left(\mathrm{CNTs}^{\mathrm{UP}}\right)$, purified $\left(\mathrm{CNTs}^{\mathrm{P}}\right)$ and oxidized $\left(\mathrm{CNTs}^{\mathrm{OX}}\right)$ carbon nanotubes were characterized in previous work, to which reference should be made to investigate their characteristics [39]. In summary, they had the following thermal characteristics, shown in Table 1.

Table 1. Thermal characteristics of non-purified $\left(\mathrm{CNTs}^{\mathrm{UP}}\right)$, purified $\left(\mathrm{CNTS}^{\mathrm{P}}\right)$, oxidized $\left(\mathrm{CNTs}^{\mathrm{OX}}\right)$ nanotubes and calcined $\left(\mathrm{CNTs}^{900}\right)$.

\begin{tabular}{|c|c|c|c|}
\hline Carbon Nanotubes & Peaks DTG $\left({ }^{\circ} \mathrm{C}\right)$ & PeaksDTA $\left({ }^{\circ} \mathrm{C}\right)$ & Total Weight Loss (\%) \\
\hline$* \mathrm{CNTs}^{\mathrm{UP}}$ & $600(\mathrm{I})$ & 612 (exo) & 92 \\
\hline${ }^{*} \mathrm{CNTs}^{\mathrm{P}}$ & $600(\mathrm{I})$ & $\begin{array}{l}606 \text { (exo) } \\
620 \text { (exo) }\end{array}$ & 100 \\
\hline$* \mathrm{CNTs}^{\mathrm{OX}}$ & $\begin{array}{c}48.12 \text { (I) } \\
470.32 \text { (II) } \\
611.32 \text { (III) } \\
695.73 \text { (IV) }\end{array}$ & $\begin{array}{l}56.90 \text { (endo) } \\
468.53 \text { (exo) } \\
604.17 \text { (exo) } \\
693.13 \text { (exo) }\end{array}$ & 99.4 \\
\hline $\mathrm{CNTs}^{900}$ & $\begin{array}{c}48.4 \text { (I) } \\
637.11 \text { (II) }\end{array}$ & $628.92(\mathrm{exo})$ & 100 \\
\hline
\end{tabular}

Unpurified nanotubes $\left(\mathrm{CNTs}^{\mathrm{UP}}\right)$ show a total weight loss of approx. 92\%, suggesting that the material is not completely burned. This means that the catalyst is still present in the sample, with a composition of approx. $8 \%$ wt of the total weight. They exhibit a single DTG peak at approx. $600{ }^{\circ} \mathrm{C}$ related to weight loss. The exothermic DTA peak at about $612{ }^{\circ} \mathrm{C}$ is due to the combustion of carbon nanotubes and is indicative of a good graphitization of the product, while the lack of exothermic peaks at temperatures below $600{ }^{\circ} \mathrm{C}$ denotes the 
absence of amorphous phases (in the range $300-350{ }^{\circ} \mathrm{C}$ ) or synthesized products with low graphitization quality (range $350-450^{\circ} \mathrm{C}$ ). Furthermore, the well-defined DTA peak shows a homogeneous graphitization of the sample.

The purified carbon nanotubes $\left(\mathrm{CNTs}^{\mathrm{P}}\right)$ show a total weight loss corresponding to $100 \%$, accompanied by a corresponding DTG peak at $600^{\circ} \mathrm{C}$, showing that the purification step is well performed.

They exhibit two exothermic DTA peaks: the first at approx. $606^{\circ} \mathrm{C}$ and the second at approx. $620^{\circ} \mathrm{C}$. The presence of an exothermic peak at a higher temperature denotes the presence of a part of nanotubes with a very high graphitization. Therefore, it is possible to hypothesize that the purification process improves the graphitization properties of $\mathrm{CNTs}^{\mathrm{P}}$ by eliminating the defects introduced during the synthesis.

The weight losses of oxidized carbon nanotubes (CNTs $\mathrm{OX}$ ) are close to $99.4 \%$, indicating that they are highly pure. The DTG peaks are four and linked to four different weight losses and exactly at $48.12{ }^{\circ} \mathrm{C}$ (weight loss $8.2 \%$ ), $470.32{ }^{\circ} \mathrm{C}$ (weight loss $6.7 \%$ ), $611.32{ }^{\circ} \mathrm{C}$ (weight loss $56.2 \%$ ) and a shoulder at $695.73{ }^{\circ} \mathrm{C}$ (weight loss $28.3 \%$ ). The DTA peaks are also four peaks, of which the first endothermic at $56.90^{\circ} \mathrm{C}$ can be attributed to the loss of humidity due to an induced hydrophilic character of the nanotubes following the oxidation treatment, which allowed immediate water adsorption before analysis. The weight loss at $468.53^{\circ} \mathrm{C}$ could be related to CNTs with lower thermal resistance related to oxidation, while the third exothermic peak, connected with a weight loss at $604.17^{\circ} \mathrm{C}$, is typical of carbon nanotubes. The weight loss at $693.13{ }^{\circ} \mathrm{C}$ could be attributed to CNTs with a higher degree of graphitization [39].

Carbon nanotubes calcined at $900{ }^{\circ} \mathrm{C}\left(\mathrm{CNTs}{ }^{900}\right)$, on the other hand, were characterized in this work by TG, DTA and DTG thermal analysis (Table 1).

The TG curve shows, as expected, that the weight loss is $100 \%$, this is because the calcined carbon nanotubes were prepared starting from the purified nanotubes, and therefore traces of the catalyst were no longer present. The DTG curve shows two peaks, the first not very evident below $100^{\circ} \mathrm{C}$. The second DTG peak is at $637.11^{\circ} \mathrm{C}$

From the DTA thermal curves, it can be seen that the $\mathrm{CNTs}^{900}$ have an exothermic DTA peak around $628.92{ }^{\circ} \mathrm{C}$. This means that the nanotubes obtained by calcination at $900^{\circ} \mathrm{C}$ have a higher degree of graphitization than CNTS UP which have a lower DTA peak. Furthermore, compared with oxidized nanotubes, they have a single peak at a temperature above $600{ }^{\circ} \mathrm{C}$, which denotes a more homogeneous graphitization, although the peak does not reach the higher temperature of $693.13{ }^{\circ} \mathrm{C}$, which can be attributed to a fraction of nanotubes of highly graphitized CNTs ${ }^{\mathrm{OX}}$ carbon.

\subsection{Adsorption of Benzoic Acid on CNTs}

From the data shown in Figure 3 it is possible to highlight that the four different types of nanotubes, all allow a lowering of the concentration of benzoic acid, albeit in a different way, confirming a general high adsorbing capacity toward benzoic acid.

Purified nanotubes $\left(\mathrm{CNTs}^{\mathrm{P}}\right)$ seem to be the worse adsorption agents. In fact, the amount of solute is reduced up to $50 \%$ of total concentration after $1.5 \mathrm{~h}$ of adsorption treatment.

Unpurified CNTs ${ }^{\mathrm{UP}}$ are better adsorption agents if compared with the $\mathrm{CNTs}^{\mathrm{P}}$. This type of CNTs can decrease the acidic concentration up to $50 \%$ after $0.5 \mathrm{~h}$, reaching a stable value after of treatment.

This performance improvement may be due to the presence of the catalyst bonded to the carbon nanotubes which, as reported, consists of zeolitic material which also has an adsorbent character. It has also been noted that non-purified carbon nanotubes have a higher dispersion in water than purified ones, probably due to the presence of the zeolite material, which is hydrophilic. Additionally, they were in the presence of a catalyst that physically reduces the formation of agglomerates of nanotubes.

This greater dispersing capacity could positively influence the final adsorbing capacity of the non-purified carbon nanotubes. 
Oxidized carbon nanotubes are highly efficient in removing benzoic acid, in fact after 10 min the concentration of benzoic acid is reduced by about $50 \%$. This high adsorbing capacity is due to the presence of carboxylated groups generated by the oxidation treatment, which interact with the benzoic acid molecules.
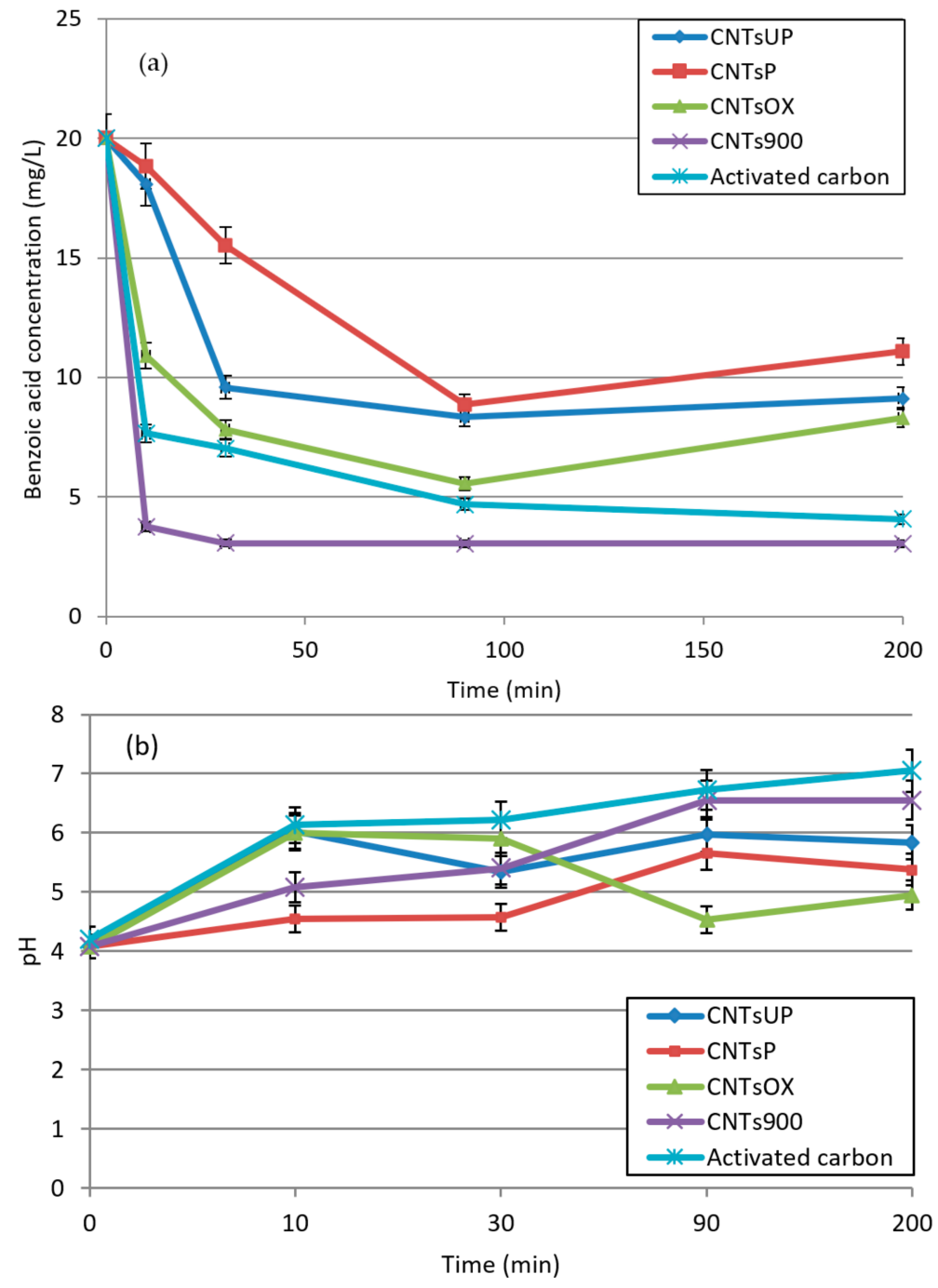

Figure 3. (a) Concentration of the benzoic acid and (b) $\mathrm{pH}$ after adsorption process as a function of time for unpurified $\left(\mathrm{CNTs}^{\mathrm{UP}}\right)$; purified $\left(\mathrm{CNTs}^{\mathrm{P}}\right)$; oxidized $\left(\mathrm{CNTs}^{\mathrm{OX}}\right)$; calcined $\left(\mathrm{CNTs}^{900}\right)$ carbon nanotubes and activated carbon.

$\mathrm{CNTs}^{900}$ show to have the highest adsorption capacity. The calcination treatment promotes the breakdown of interactions between nanotubes, which cause the formation of aggregates of nanotubes, with the consequence of having a better dispersion in the adsorption system.

In fact, the color of the acidic solution after introduction of CNTs ${ }^{900}$ is completely black, while it is possible to note black aggregates during the adsorption treatment with other kinds of nanotubes.

Considering a 30 min average time, the efficiency scale is: $\mathrm{CNTs}^{900}>\mathrm{CNTs}^{\mathrm{OX}}>$ $\mathrm{CNTS}^{\mathrm{UP}}>\mathrm{CNT}^{\mathrm{P}}$, for which the concentrations of benzoic acid after the adsorption tests are, respectively, 3.06, 7.81, 9.58 and $15.53 \mathrm{mg} / \mathrm{L}$.

Adsorption of benzoic acid was carried out under the same previous conditions, but with activated carbon in order to be able to draw a comparison with the different adsorbent materials used. The results obtained show that $\mathrm{CNTs}^{900}$ exhibit better adsorbing properties 
than activated carbon. The $\mathrm{pH}$ values of the solution tend to increase as the contact times increase, in perfect consistency with the reduction in acid concentration.

The following Figure 4 shows the percentage by weight of benzoic acid adsorbed for the different types of carbon nanotubes as a function of the contact time.

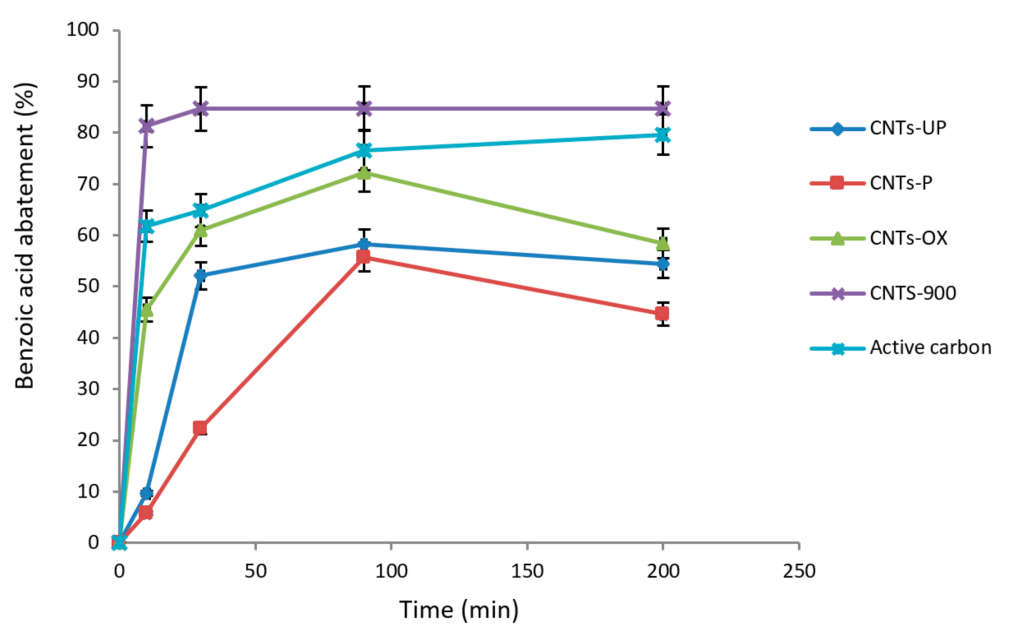

Figure 4. Benzoic acid abatement (\%) as a function of contact time for different adsorbent materials.

The data reported show that carbon nanotubes calcined at $900{ }^{\circ} \mathrm{C}$ reach a reduction of about $80 \%$ already in the first ten minutes. For the other types of carbon nanotubes, the highest abatement $\%$ is reached at a time of $90 \mathrm{~min}$, with values around $72 \%, 56 \%, 58 \%$, respectively, for $\mathrm{CNTs}^{\mathrm{OX}}, \mathrm{CNTs}^{\mathrm{UP}}$ and $\mathrm{CNTs}^{\mathrm{P}}$.

\subsection{Adsorption Capacity}

The adsorption capacity was studied using the following Equation:

$$
q_{e}=\frac{m_{\text {adsorbed }}}{m_{\text {adsorbent }}}=\frac{\left(C_{i}-C_{f}\right) \cdot V}{m_{C N T s}}
$$

where $C_{i}$ and $C_{f}$ are the initial and final concentration $(\mathrm{mg} / \mathrm{L})$ of benzoic acid, respectively; $V$ is the volume of treated solution (L), $m_{\text {adsorbed }}$ represents the mass of benzoic acid adsorbed and $m_{\text {adsorbent }}$ represents the mass of carbon nanotubes. The following Figure 5 reports the adsorption capacity as a function of contact time for each type of carbon nanotube.

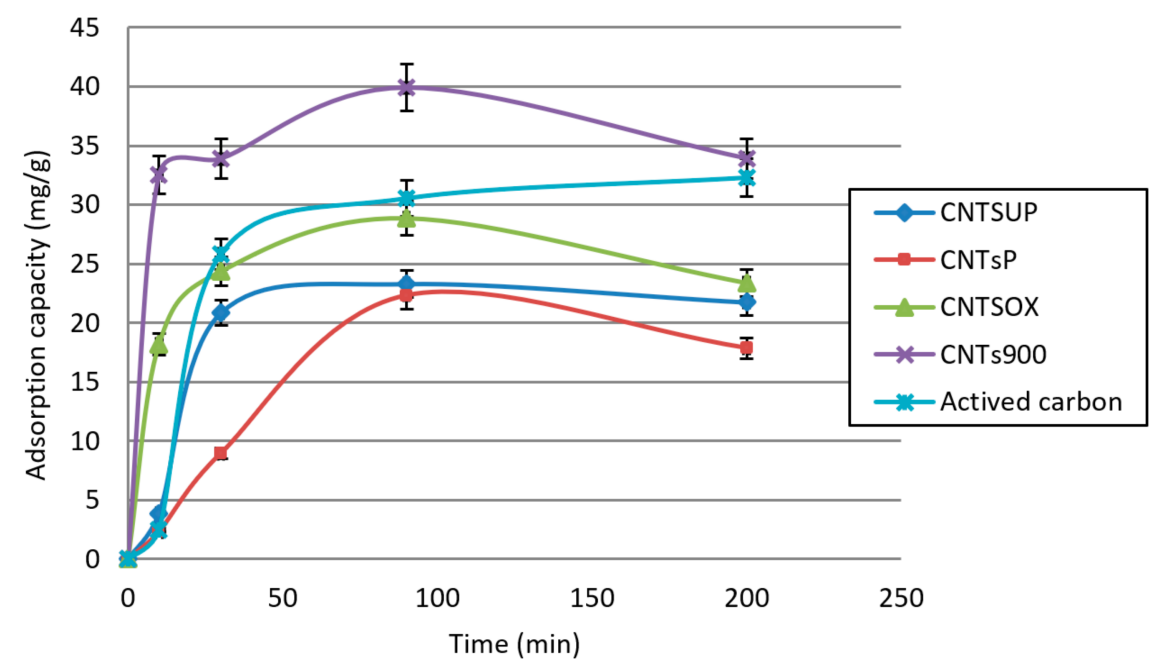

Figure 5. Adsorption capacity as a function of contact time for different carbon nanotube types. 
The data reported show that the maximum adsorption capacity for all four different types of carbon nanotubes is reached at $90 \mathrm{~min}$ of contact time. The adsorption capacity for $\mathrm{CNTs}^{900}, \mathrm{CNTs}^{\mathrm{OX}}, \mathrm{CNTs}^{\mathrm{P}}, \mathrm{CNTs}^{\mathrm{UP}}$ at $90 \mathrm{~min}$ are, respectively $39.9,28.9,23.3,22.3 \mathrm{mg} / \mathrm{g}$.

The adsorption capacity of activated carbon at $90 \mathrm{~min}$ is equal to $30.5 \mathrm{mg} / \mathrm{g}$, a value lower than that of $\mathrm{CNTs}^{900}$. All of this allows us to define the $\mathrm{CNTs}^{900}$ as the best materials among those analyzed for the adsorption of benzoic acid.

\subsection{Kinetic Study}

The adsorption rates, in the different time intervals, were calculated for each type of carbon nanotube and for the activated carbons, during the adsorption tests (Figure 6). The adsorption rates were calculated using the following expression:

$$
\text { Adsorption rate }=\left(\mathrm{C}_{2}-\mathrm{C}_{1}\right) /\left(\mathrm{t}_{2}-\mathrm{t}_{1}\right)
$$

where $C_{1}$ and $C_{2}$ represent the concentration of benzoic acid expressed in $\mathrm{mg} / \mathrm{L}$ at the contact time $t_{1}$ and $t_{2}$, respectively.

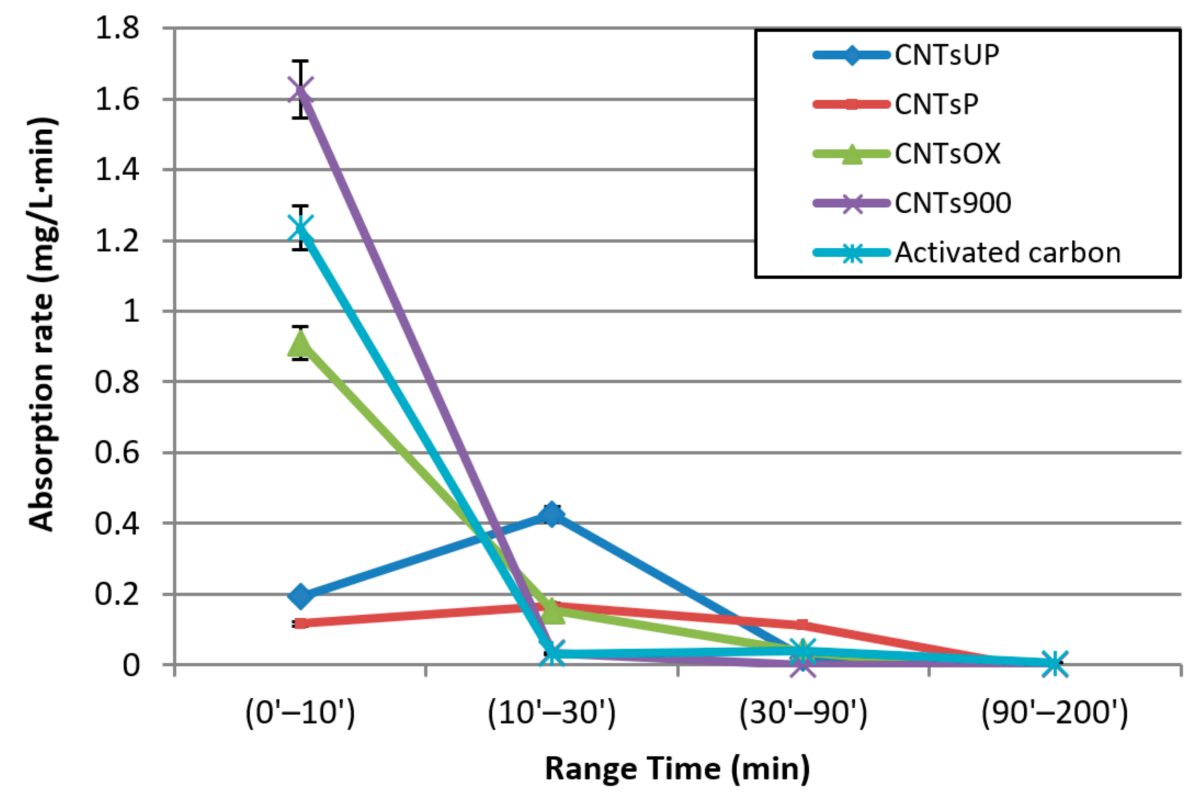

Figure 6. Adsorption rate for different adsorbent materials as a function of range time.

The time intervals considered were $\left(0^{\prime}-10^{\prime}\right) ;\left(10^{\prime}-30^{\prime}\right) ;\left(30^{\prime}-90^{\prime}\right) ;\left(90^{\prime}-200^{\prime}\right)$.

The results obtained show that $\mathrm{CNTs}^{\mathrm{UP}}$ and $\mathrm{CNTs}^{\mathrm{P}}$ reach a maximum adsorption value in the time interval $\left(10^{\prime}-30^{\prime}\right)$ and with fairly low maximum adsorption rates, respectively equal to 0.42 and $0.16 \mathrm{mg} / \mathrm{L} \cdot \mathrm{min}$. The greater efficiency of $\mathrm{CNTs}^{\mathrm{OX}}$ and CNTs ${ }^{900}$ is highlighted by shorter times, less than $10 \mathrm{~min}$, in which the maximum adsorption rate values are reached. The maximum values of the adsorption rate, also comparing them with those relating to activated carbons, are $0.9,1.2,1.6 \mathrm{mg} / \mathrm{L} \cdot \mathrm{min}$ for $\mathrm{CNTs} \mathrm{OX}_{\text {, activated }}$ carbon and CNTs ${ }^{900}$, respectively. The set of results show that $\mathrm{CNTs}^{900}$ are the best adsorbent materials among those studied, obtaining higher adsorption rate value and shorter adsorption time.

Figure 7 shows the residual concentration of benzoic acid on a logarithmic scale as a function of the contact time for $\mathrm{CNTs}^{\mathrm{UP}}, \mathrm{CNTs}^{\mathrm{P}}$ and $\mathrm{CNTs}{ }^{\mathrm{OX}}$. 

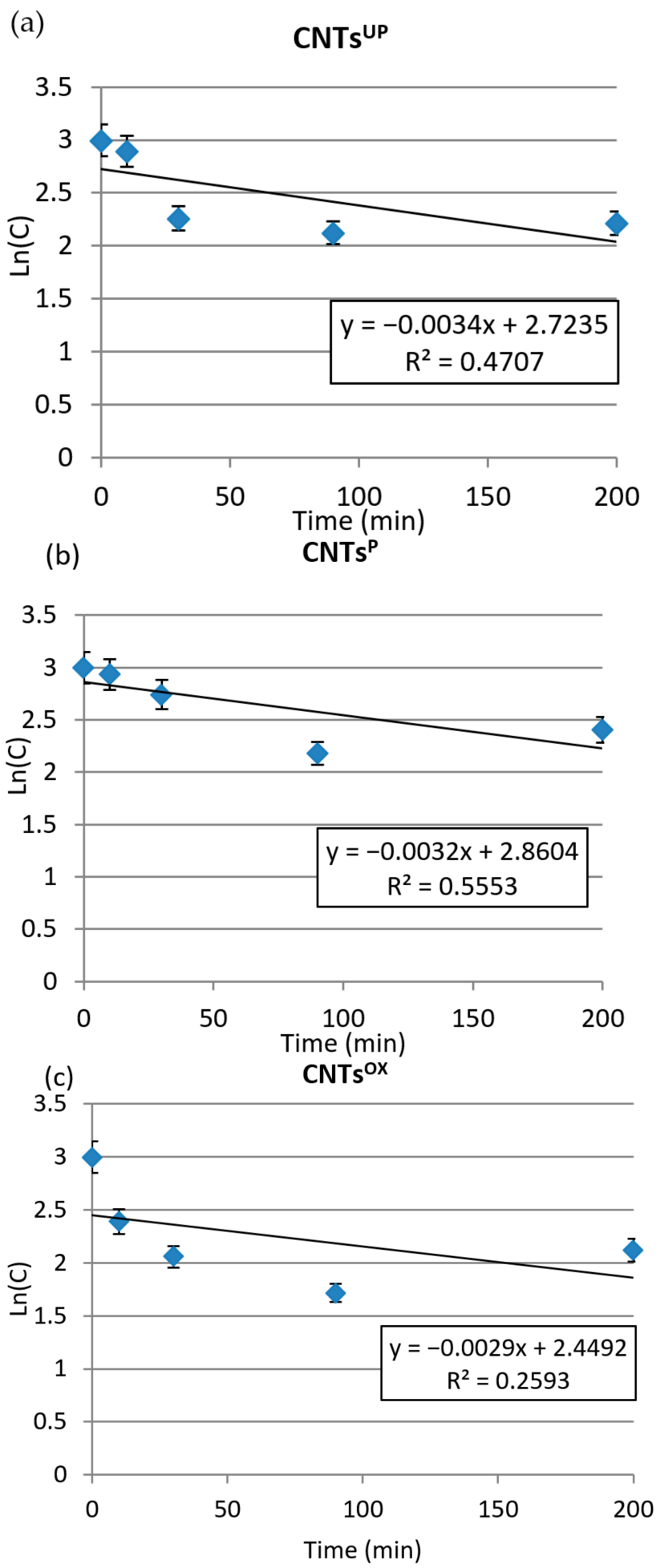

Figure 7. (a-c) Residual concentrations in logarithmic scale for $\mathrm{CNTs}^{\mathrm{UP}}, \mathrm{CNTs}^{\mathrm{P}}, \mathrm{CNTs}^{\mathrm{OX}}$ as a function of the contact time.

The adsorption of benzoic acid on $\mathrm{CNTs} \mathrm{UP}^{\mathrm{UP}}, \mathrm{CNTs}^{\mathrm{P}}$ and $\mathrm{CNTs} \mathrm{OX}^{\mathrm{O}}$ are first order because the adsorption is not very strong. The kinetic constants are $\mathrm{k}_{1}=-0.0034\left(\mathrm{~min}^{-1}\right)$; $-0.0032\left(\mathrm{~min}^{-1}\right)$ and $-0.0029\left(\mathrm{~min}^{-1}\right), \mathrm{R}^{2}=0.4707,0.5553,0.2593$ for $\mathrm{CNTs}^{\mathrm{UP}}, \mathrm{CNTs}^{\mathrm{P}}$ and $\mathrm{CNTs}^{\mathrm{OX}}$, respectively (Figure $7 \mathrm{a}-\mathrm{c}$ ). On the other hand, because the adsorption of benzoic acid is very strong on $\mathrm{CNT}^{900}$ and on activated carbon, the reaction is of zero order. The 
kinetic constant relative to the first linear segment is $\mathrm{K}_{0}=-1.626\left(\mathrm{mg} \cdot \mathrm{L}^{-1} \cdot \mathrm{min}^{-1}\right)$ and $-1.235\left(\mathrm{mg} \cdot \mathrm{L}^{-1} \cdot \mathrm{min}^{-1}\right)$ for $\mathrm{CNTs}^{900}$ and activated carbon, respectively.

\subsection{Thermal Characterization Post-Adsorption of Solid Materials}

Figure 8 shows the TG thermal curves of the different types of carbon nanotubes after the adsorption tests.

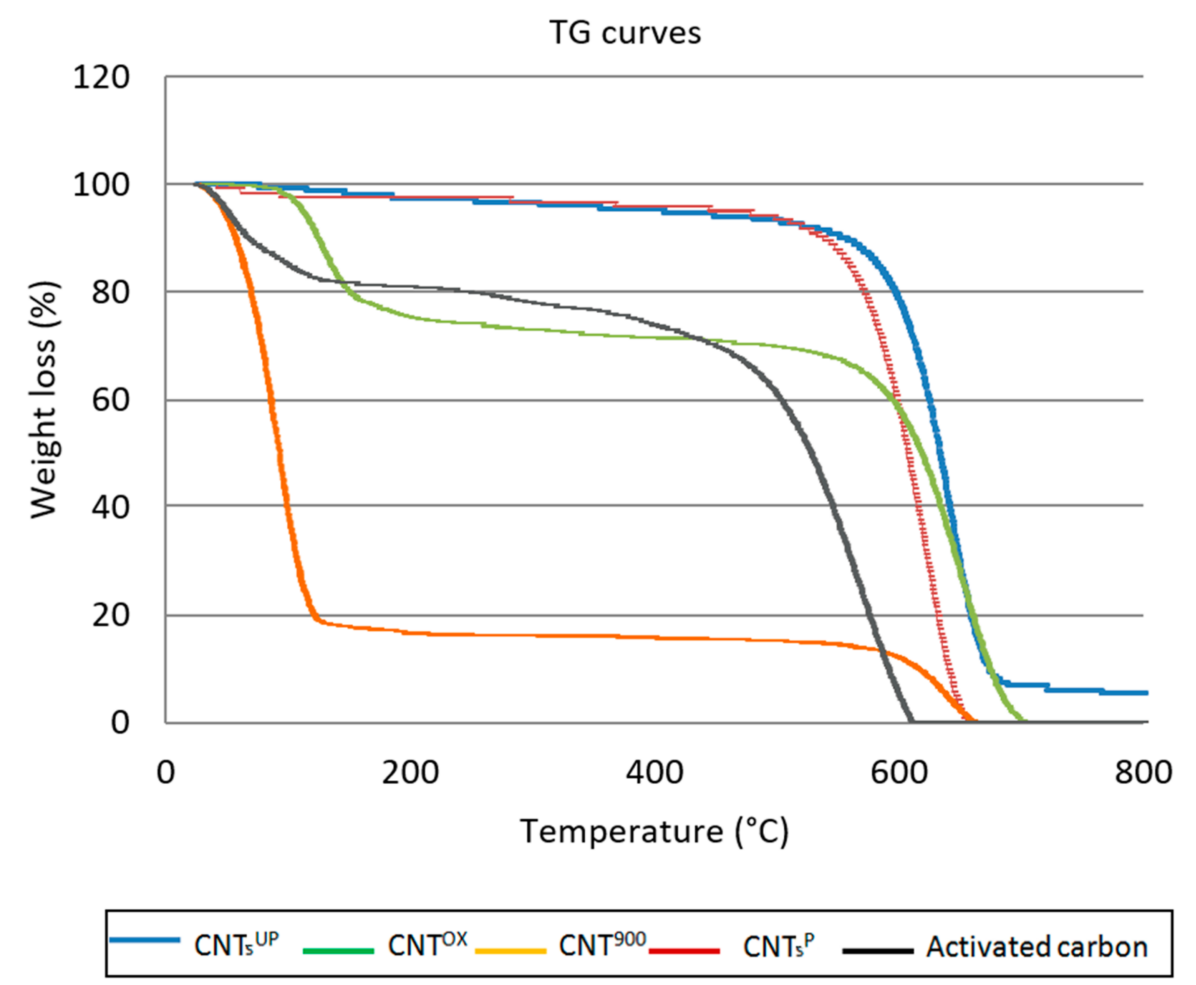

Figure 8. TG curves of the different types of carbon nanotubes and activated carbon after adsorption tests at a contact time of $90 \mathrm{~min}$.

From the thermogravimetric curves (TG) it is possible to note two main weight losses: the first occurring in the temperature range between $100{ }^{\circ} \mathrm{C}$ and $550{ }^{\circ} \mathrm{C}$ and a second between $550{ }^{\circ} \mathrm{C}$ and $800{ }^{\circ} \mathrm{C}$.

The first loss is certainly attributable to the presence of benzoic acid, as it has a melting temperature of $121-123^{\circ} \mathrm{C}$ and a boiling temperature of $249^{\circ} \mathrm{C}$. Furthermore, these losses cannot be attributed to the carbon nanotubes, as it is known that they are thermally stable up to $600{ }^{\circ} \mathrm{C}$ [39]. These losses are of a different entity in the different types of carbon nanotubes used.

The first weight losses, between $100-550{ }^{\circ} \mathrm{C}$, are very low as regards the CNTs $\mathrm{UP}$ and $\mathrm{CNTs}^{\mathrm{P}}$, with values of $10.0 \%$ and $12.3 \%$, respectively. For the $\mathrm{CNTs}^{\mathrm{OX}}$ and $\mathrm{CNTs}{ }^{900}$ samples, these are much higher with values of $32.6 \%$ and $85 \%$, respectively. These results are perfectly consistent with the abatement data, reported in the previous Section 3.1, which confirms this order of effectiveness in the removal of benzoic acid: $\mathrm{CNTs}^{900}>\mathrm{CNTs}^{\mathrm{OX}}$ $>\mathrm{CNTs}^{\mathrm{UP}}>\mathrm{CNTs}^{\mathrm{P}}$. The total weight losses are $100 \%$ except for $\mathrm{CNTs}$, which has a residual weight attributable to the presence of the catalyst, which continues to be present in this type of nanotube, having not undergone any purification treatment.

The activated carbon shows a first weight loss of $25 \%$ medium value between the $\mathrm{CNTs}^{\mathrm{UP}}$, the $\mathrm{CNTs}^{\mathrm{P}}$, and the $\mathrm{CNTs}^{\mathrm{OX}}$ and the $\mathrm{CNTs}^{900}$, respectively.

The following Figure 9 reports the thermal curves DTg and DTA of the carbon nanotubes after the adsorption tests. 


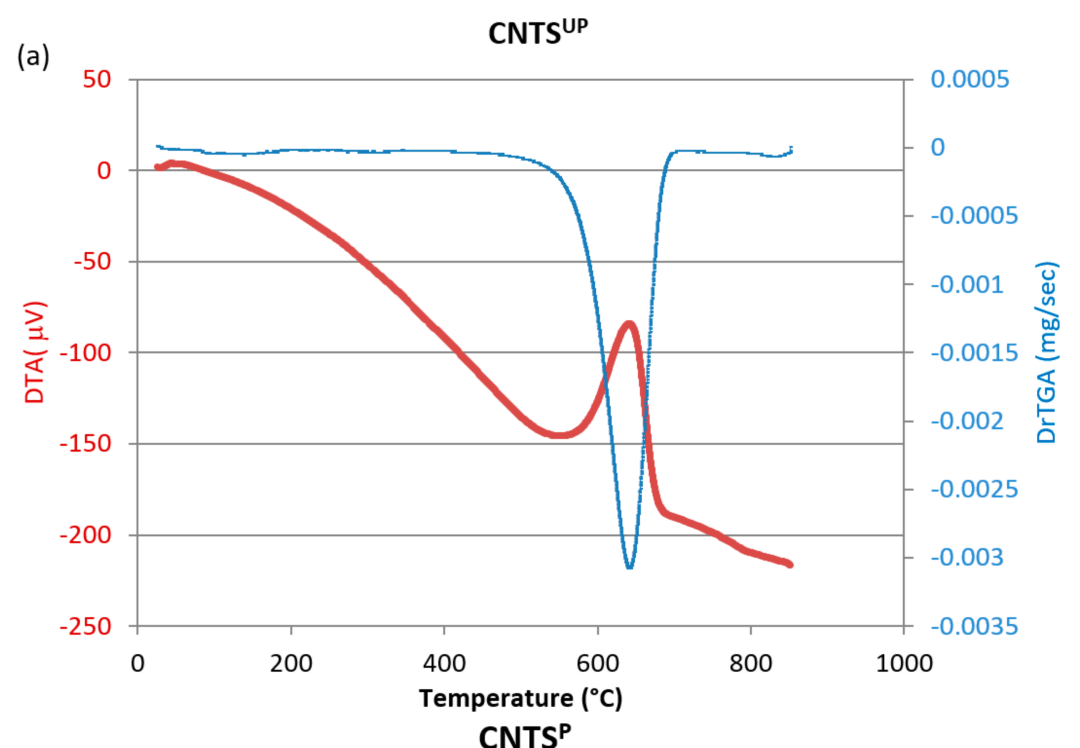

(b)

CNTS $^{P}$

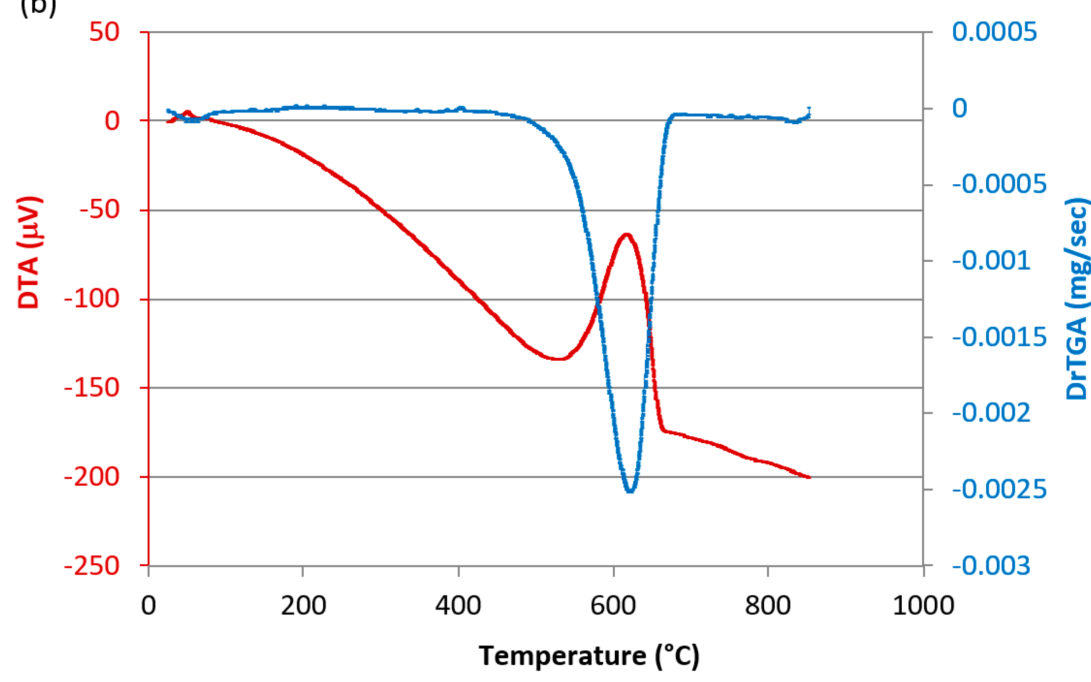

(c)

CNTS ${ }^{\circ}$

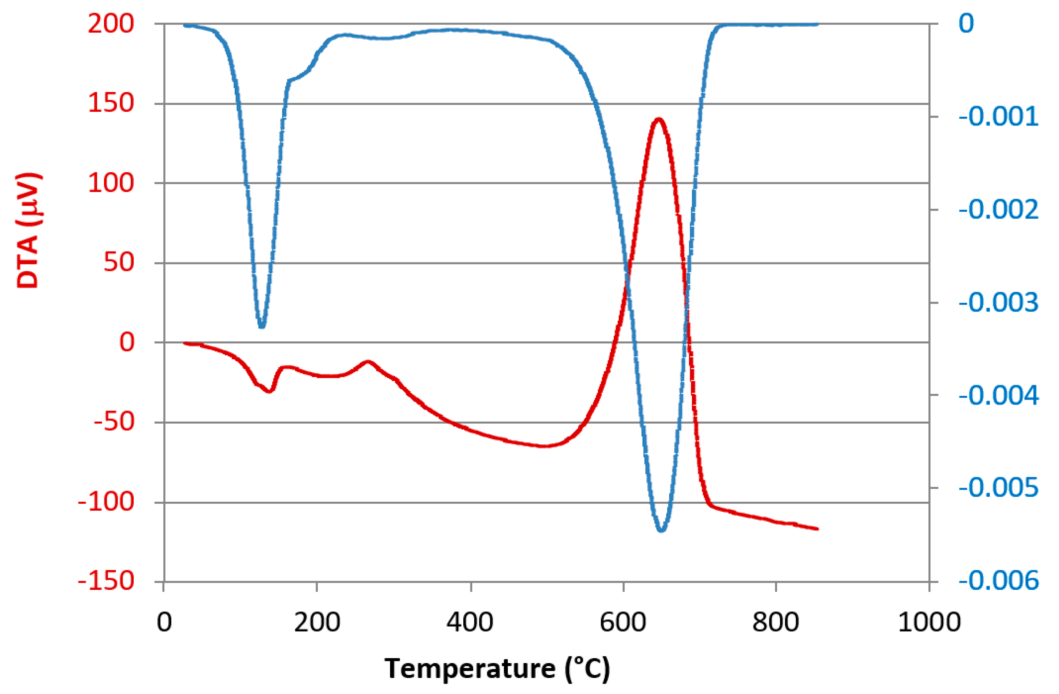

Figure 8. Cont. 


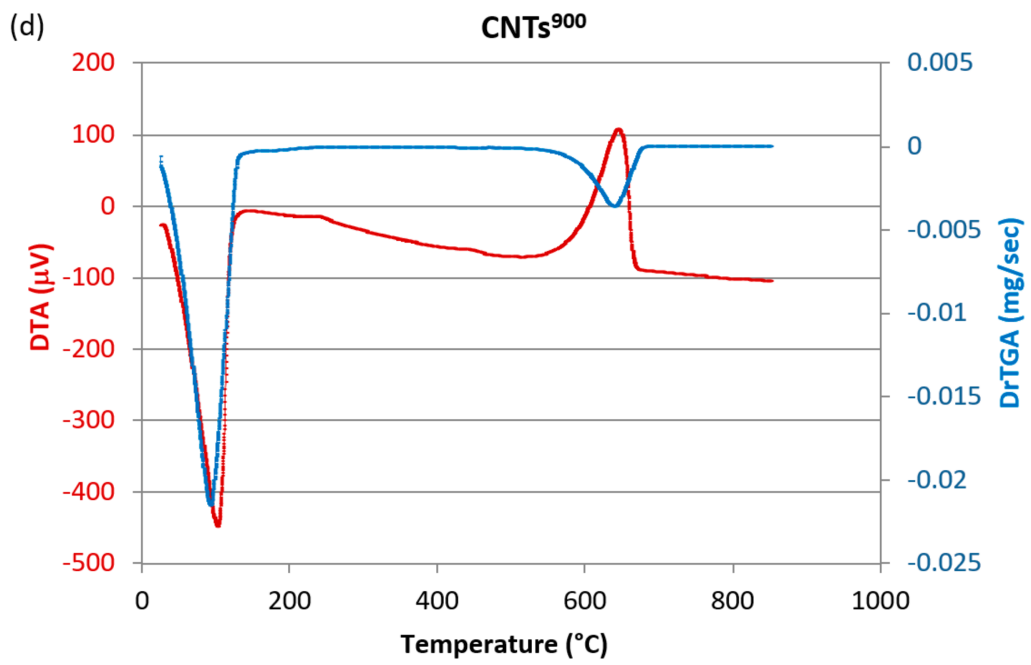

Figure 9. DTG and DTA curves of (a) purified; (b) unpurified; (c) oxidized; (d) calcined carbon nanotubes after benzoic acid adsorption tests for a contact time of $90 \mathrm{~min}$.

The DTA curves show endothermic peaks at temperatures below $200{ }^{\circ} \mathrm{C}$, which are very evident for $\mathrm{CNTs}^{\mathrm{OX}}$ and $\mathrm{CNTs}^{900}$, as they adsorbed a greater quantity of benzoic acid. These endothermic DTA peaks, accompanied by corresponding DTG peaks, can be attributed to the melting and loss of benzoic acid. In the case of CNTs ${ }^{\mathrm{OX}}$ there is also a second endothermic DTA peak, accompanied by a corresponding DTG peak, just over $200^{\circ} \mathrm{C}$, which can be attributed to the interactions of benzoic acid with carboxylic groups present on the functionalized surface of the nanotubes. At temperatures above $600{ }^{\circ} \mathrm{C}$, an exothermic DTA peak is evidently present in all the samples, accompanied by a corresponding DTG peak, which is attributable to the combustion of carbon nanotubes.

\subsection{SEM Characterization}

The observation by the electron microscope (SEM) of carbon nanotubes after the adsorption tests offered useful information to understand the adsorption mechanism of benzoic acid.

Unpurified nanotubes $\left(\mathrm{CNTs}^{\mathrm{UP}}\right)$ appear massed, not sufficiently separated and with white spots on the surface attributable to benzoic acid Figure 10a.

The purified nanotubes $\left(\mathrm{CNT}^{\mathrm{P}}\right)$ have the classic organization in bundles with dimensions between 10-50 nm. Small white spots denote the presence of benzoic acid on the surface but in less quantity than in non-purified carbon nanotubes Figure 10b.

Oxidized nanotubes $\left(\mathrm{CNTs}^{\mathrm{OX}}\right)$ also have small white spots on the surface attributable to benzoic acid. In this case, the presence of functional groups, generated by the oxidation treatment, of the - $\mathrm{COOH}$ type guarantee an improvement in the acid adsorption process on the surface of the nanotubes Figure 10c.

The carbon nanotubes calcined at $900{ }^{\circ} \mathrm{C}$ have a certainly greater quantity of benzoic acid on the surface than in the other previous cases, which is consistent with the adsorption data reported in Section 3.1, in which the calcined carbon nanotubes are the most efficient of all Figure 10d.

In light of the data obtained, it is possible to state that the different adsorption capacities of the carbon nanotubes used are due to the establishment of distinct phenomena.

In general, adsorption can take place inside the carbon nanotubes or on their surface.

The adsorption on the surface is favored the freer the surface and the greater the separation between the nanotubes. Furthermore, the presence of functional groups on the surface of the nanotubes, such as carboxyl groups, increases their surface adsorption. Even in the absence of functional groups, the adsorption of benzoic acid on the surface is guaranteed by molecular interaction. 

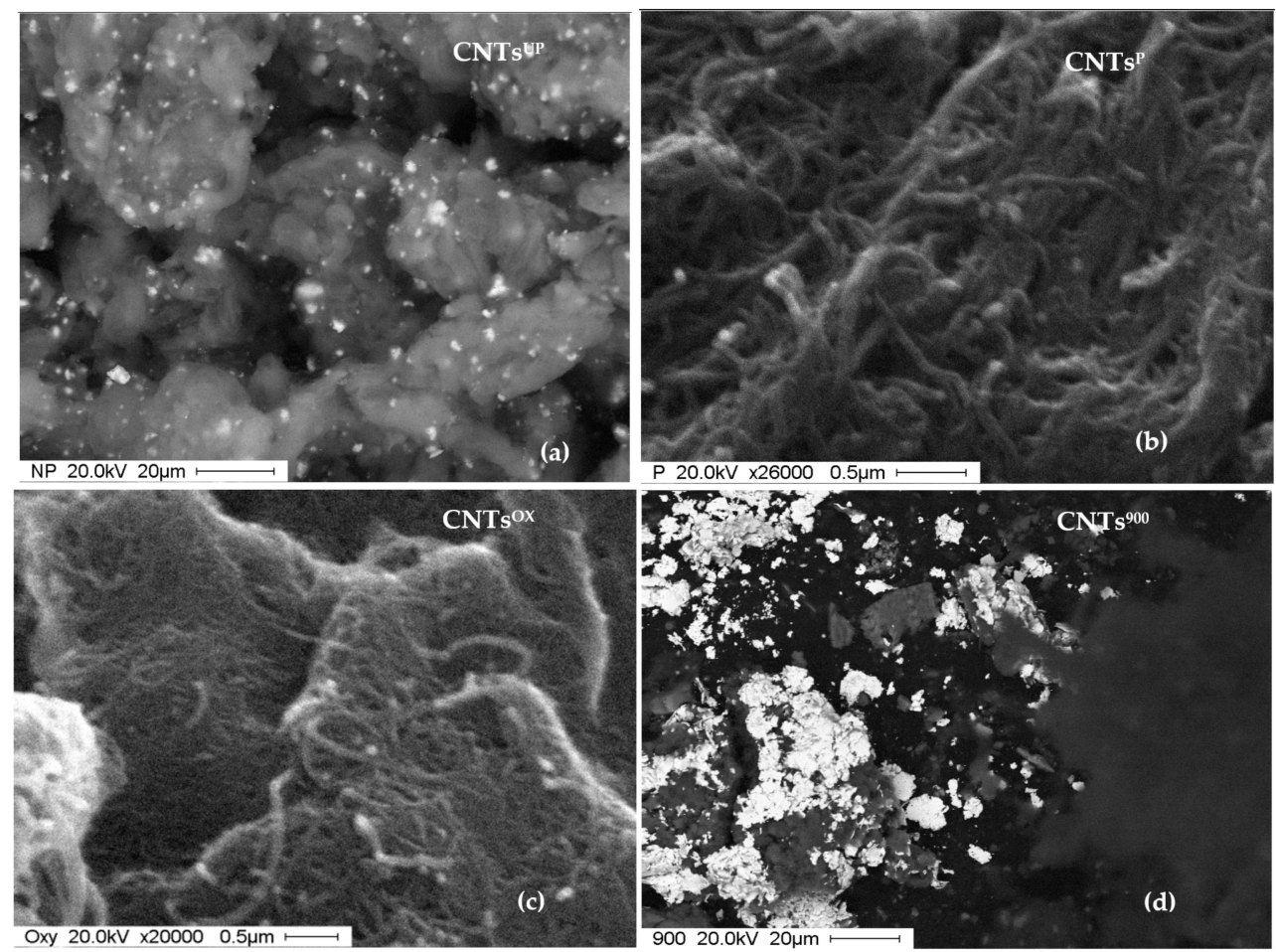

Figure 10. SEM images of the (a) purified; (b) unpurified; (c) oxidized; (d) calcined nanotubes after the adsorption test at a contact time of $90 \mathrm{~min}$.

Adsorption within the carbon nanotubes is favored by the accessibility of the channels, which depends on a good dispersion of the nanotubes, determined by the absence of agglomerates. Another determining factor is the presence of clean channels, which must be free of amorphous material.

Each of the different treatments carried out on the carbon nanotubes (purification, oxidation, calcination) specifically favors the different adsorption methods, favoring some of them more than others.

In particular, in the purification process, there is the destruction of the zeolite material used as the base of the catalyst. The latter also has an adsorbing capacity; therefore, the better adsorption efficiency of non-purified nanotubes compared with purified ones can be justified by the concomitant presence of microporous adsorbing material.

The oxidation of the nanotubes promotes the superficial adsorption of benzoic acid thanks to the formation of carboxylic groups that promote the reaction with benzoic acid. In addition, it also has a partial cleaning effect of the channels, also favoring an improvement in adsorption within the channels.

Calcination at $900{ }^{\circ} \mathrm{C}$ has the predominant effect of destroying interactions between the different nanotubes and therefore of making the carbon nanotubes free of clusters and agglomerates, making them optimally dispersible in water. All this means that the calcination at $900{ }^{\circ} \mathrm{C}$, under nitrogen, allows the carbon nanotubes to play their role fully and optimally as adsorbent materials for the removal of benzoic acid.

The importance of the interaction between the nanotubes was highlighted in an excellent paper by Wisniewski et al. [41]. They have shown that the adsorption of benzene greatly depends on the diameter of the nanotubes and the number of concentric layers. This is due to the formation of interstitial channels within the bundles. However, the individual nanotubes represent the best adsorbing surface, as it is also shown in the present paper. 


\section{Conclusions}

In general, all the different types of carbon nanotubes-CNTs ${ }^{\mathrm{UP}}, \mathrm{CNTs}^{\mathrm{P}}, \mathrm{CNTs}^{\mathrm{OX}}$, $\mathrm{CNTs}^{900}$ - showed the ability to adsorb benzoic acid from aqueous solutions, although with different intensities.

The purification treatment leads to a slight lowering of efficiency compared with non-purified carbon nanotubes. This is to be attributed to the fact that the purification, in addition to destroying the catalyst, which is also an adsorbent material and which hinders agglomeration due to its presence, makes the nanotubes less dispersed.

The oxidation and calcination pretreatments at $900{ }^{\circ} \mathrm{C}$ proved to be decisive for increasing the adsorption capacity. The oxidation process, which leads to the formation of carboxylic groups, adds a further possibility for the benzoic acid molecules to interact on the surface of the nanotubes, improving the adsorbent performance compared with purified and non-purified nanotubes.

The $900{ }^{\circ} \mathrm{C}$ pretreatment of carbon nanotubes was shown to be the best, compared with all types of nanotubes used in this research. In fact, this treatment leads to an important elimination of clusters and therefore to the breakdown of the interactions between the nanotubes, significantly increasing the adsorption surface. An evident effect of this treatment is a complete and uniform dispersion and absence of agglomerates of the CNTs ${ }^{900}$ when they are inserted in the benzoic acid solution.

The $\mathrm{CNTs}^{900}$ reach a reduction of benzoic acid of about $80 \%$ already in the first ten minutes. For the other types of carbon nanotubes, the highest percentage abatement is reached at a time of $90 \mathrm{~min}$, with values of $72 \%, 56 \%, 58 \%$ for $\mathrm{CNTs}^{\mathrm{OX}}, \mathrm{CNTs}^{\mathrm{UP}}$ and $\mathrm{CNTs}^{\mathrm{P}}$, respectively. Moreover, $\mathrm{CNTs}^{900}$ performed better than activated carbon.

Thanks to the results obtained, it is possible to say that the efficiency scale of the different types of nanotubes with respect to the adsorption of benzoic acid from aqueous solutions follows the order: $\mathrm{CNTs}^{900}>\mathrm{CNTs}^{\mathrm{OX}}>\mathrm{CNTS}^{\mathrm{UP}}>\mathrm{CNT}^{\mathrm{P}}$.

Author Contributions: Conceptualization, P.D.L. and C.S.; methodology, P.D.L. and A.M.; validation, P.D.L. and C.S.; formal analysis, P.D.L.; investigation, C.S. and A.M.; data curation, C.S.; writingreview and editing, C.S., P.D.L. and J.B.N.; supervision, P.D.L. and J.B.N. All authors have read and agreed to the published version of the manuscript.

Funding: This research received no external funding.

Institutional Review Board Statement: Not applicable.

Informed Consent Statement: Not applicable.

Data Availability Statement: Data are contained within the article.

Conflicts of Interest: The authors declare no conflict of interest.

\section{References}

1. Iijima, S. Helical microtubules of graphitic carbon. Nature 1991, 56, 354. [CrossRef]

2. Iijima, S. Carbon nanotubes: Past, present, and future. Phys. Rev. B Condens. 2002, 323, 1-5. [CrossRef]

3. Eatemadi, A.; Daraee, H.; Karimkhanloo, H.; Kouhi, M.; Zarghami, N.; Akbarzadeh, A.; Abasi, M.; Hanifehpour, Y.; Joo, S.W. Carbon nanotubes: Properties, synthesis, purification, and medical applications. Nanoscale Res. Lett. 2014, 9, 393. [CrossRef]

4. Harris, P.J.F.; Hernández, E.; Yakobson, B.I. Carbon Nanotubes and Related Structures: New Materials for the Twenty-First Century. Am. J. Phys. 2004, 72, 415. [CrossRef]

5. Mauter, M.S.; Elimelech, M. Environmental applications of carbon-based nanomaterials. Environ. Sci. Technol. 2008, 42, 5843-5859. [CrossRef]

6. Sarkar, B.; Mandal, S.; Tsang, Y.F.; Kumar, P.; Kim, K.-H.; Ok, Y.S. Designer carbon nanotubes for contaminant removal in water and wastewater: A critical review. Sci. Total Environ. 2018, 612, 561-581. [CrossRef] [PubMed]

7. Ma, L.; Dong, X.; Chen, M.; Zhu, L.; Wang, C.; Yang, F.; Dong, Y. Fabrication and water treatment application of carbon nanotubes (cnts)-based composite membranes: A review. Membranes 2017, 7, 16. [CrossRef]

8. Upadhyayula, V.K.K.; Deng, S.; Mitchell, M.C.; Smith, G.B. Application of carbon nanotube technology for removal of contaminants in drinking water: A review. Sci. Total Environ. 2009, 408, 1-13. [CrossRef]

9. Goh, K.; Karahan, H.E.; Wei, L.; Bae, T.-H.; Fane, A.G.; Wang, R.; Chen, Y. Carbon nanomaterials for advancing separation membranes: A strategic perspective. Carbon 2016, 109, 694-710. [CrossRef] 
10. Hokkanen, S.; Bhatnagar, A.; Sillanpää, M. A review on modification methods to cellulose-based adsorbents to improve adsorption capacity. Water Res. 2016, 91, 156-173. [CrossRef]

11. Bentahar, S.; Dbik, A.; El Khomri, M.; El Messaoudi, N.; Lacherai, A. Removal of a cationic dye from aqueous solution by natural clay. Groundw. Sustain. Dev. 2018, 6, 255-262. [CrossRef]

12. Crini, G.; Badot, P.M. Application of chitosan, a natural aminopolysaccharide, for dye removal from aqueous solutions by adsorption processes using batch studies: A review of recent literature. Prog. Polym. Sci. 2008, 33, 399-447. [CrossRef]

13. Vakili, M.; Rafatullah, M.; Salamatinia, B.; Abdullah, A.Z.; Ibrahim, M.H.; Tan, K.B.; Gholami, Z.; Amouzgar, P. Application of chitosan and its derivatives as adsorbents for dye removal from water and wastewater: A review. Carbohydr. Polym. 2014, 113, 115-130. [CrossRef] [PubMed]

14. Namasivayam, C.; Kavitha, D. Removal of Congo Red from water by adsorption onto activated carbon prepared from coir pith, an agricultural solid waste. Dye. Pigment. 2002, 54, 47-58. [CrossRef]

15. Purkait, M.K.; Das Gupta, S.; De, S. Adsorption of eosin dye on activated carbon and its surfactant based desorption. J. Environ. Manag. 2005, 76, 135-142. [CrossRef] [PubMed]

16. De Luca, P.; Bernaudo, I.; Elliani, R.; Tagarelli, A.; Nagy, J.B.; Macario, A. Industrial Waste Treatment by ETS-10 Ion Exchanger Material. Materials 2018, 11, 2316. [CrossRef]

17. Bandura, L.; Franus, M.; Madej, J.; Kołodynska, D.; Hubicki, Z. Zeolites in Phenol Removal in the Presence of Cu(II) IonsComparison of Sorption Properties after Chitosan Modification. Materials 2020, 13, 643. [CrossRef] [PubMed]

18. Yang, K.L.; Zhu, B.X. Adsorption of Polycyclic Aromatic Hydrocarbons by Carbon Nanomaterials. Environ. Sci. Technol. 2006, 40, 1855-1861. [CrossRef] [PubMed]

19. Lico, D.; Vuono, D.; Siciliano, C.; Nagy, J.B.; De Luca, P. Removal on unleaded gasoline from water by multi-walled carbon nanotubes. J. Environ. Manag. 2019, 237, 636-643. [CrossRef] [PubMed]

20. Gotovac, S.; Yang, C.M.; Hattori, Y.; Takahashi, K.; Kanoh, H.; Kaneko, K. Adsorption of polyaromatic hydrocarbons on single wall carbon nanotubes of different functionalities and diameters. J. Colloid Interface Sci. 2007, 314, 18-24. [CrossRef]

21. Lu, C.; Su, F.; Hu, S. Surface modification of carbon nanotubes for enhancing BTEX adsorption from aqueous solutions. Appl. Surf. Sci. 2008, 254, 7035-7041. [CrossRef]

22. Machado, F.M.; Bergmann, C.P.; Fernandes, T.H.M.; Lima, E.C.; Royer, B.; Calvete, T.; Fagan, S.B. Adsorption of Reactive Red M-2BE dye from water solutions by multi-walled carbon nanotubes and activated carbon. J. Hazard. Mater. 2011, 192, 1122-1131. [CrossRef]

23. De Benedetto, C.; Macario, A.; Siciliano, C.; Nagy, J.B.; De Luca, P. Adsorption of Reactive Blue 116 Dye and Reactive Yellow 81 Dye from Aqueous Solutions by Multi-Walled Carbon Nanotubes. Materials 2020, 13, 2757. [CrossRef] [PubMed]

24. Duman, O.; Tunç, S.; Polat, T.G.; Bozoğlan, B.K. Synthesis of magnetic oxidized multiwalled carbon nanotube r546464-kcarrageenan-Fe3O4 nanocomposite adsorbent and its application in cationic Methylene Blue dye adsorption. Carbohydr. Polym. 2016, 147, 79-88. [CrossRef]

25. De Luca, P.; Nagy, J.B. Treatment of Water Contaminated with Reactive Black-5 Dye by Carbon Nanotubes. Materials 2020, 13, 5508. [CrossRef] [PubMed]

26. De Luca, P.; Chiodo, A.; Macario, A.; Siciliano, C.; Nagy, J.B. Semi-Continuos Adsorption Processes with Multi-Walled Carbon Nanotubes for treatment of water contaminated by an Organic Tixtile Dye. Appl. Sci. 2021, 11, 1687. [CrossRef]

27. Ihsanullah, I.; Al-Khaldi, F.A.; Abu-Sharkh, B.; Abulkibash, A.M.; Qureshi, M.I.; Laoui, T.; Atieh, M.A. Effect of acid modification on adsorption of hexavalent chromium $(\mathrm{Cr}(\mathrm{VI}))$ from aqueous solution by activated carbon and carbon nanotubes. Desalin. Water Treat. 2016, 57, 7232-7244. [CrossRef]

28. Lu, C.; Liu, C. Removal of nickel(II) from aqueous solution by carbon nanotubes. J. Chem. Technol. Biotechnol. 2006, 81, 1932-1940. [CrossRef]

29. Stafiej, A.; Pyrzynska, K. Adsorption of heavy metal ions with carbon nanotubes. Sep. Purif. Technol. 2007, 58, 49-52. [CrossRef]

30. Xin, X.; Si, W.; Yao, Z.; Feng, R.; Du, B.; Yan, L.; Wei, Q. Adsorption of benzoic acid from aqueous solution by three kinds of modified bentonites. J. Colloid Interface Sci. 2011, 359, 499-504. [CrossRef]

31. Lee, P.Y.; Chen, C.Y. Toxicity and quantitative structure-activity relationships of benzoic acids to Pseudokirchneriella subcapitata. J. Hazard. Mater. 2009, 165, 156-161. [CrossRef]

32. Muccini, M.; Layton, A.C.; Sayler, G.S.; Schultz, T.W. Aquatic toxicities of halogenated benzoic acids to Tetrahymena pyriformis Bull. Environ. Contam. Toxicol. 1999, 62, 616-622. [CrossRef]

33. Kamaya, Y.; Fukaya, Y.; Suzuki, K. Acute toxicity of benzoic acids to the crustacean Daphnia magna. Chemosphere 2005, 59, 255-261. [CrossRef] [PubMed]

34. Kotel, L.Y.; Brichka, A.V.; Brichka, S.Y. Adsorption properties of modified multilayer carbon nanotubes with respect to benzoic acid. Russian J. Appl. Chem. 2009, 82, 569.

35. Dai, J.; Xiao, X.; Duan, S.; Liu, J.; He, J.; Lei, J.; Wang, L. Synthesis of novel microporous nanocomposites of ZIF-8 on multiwalled carbon nanotubes for adsorptive removing benzoic acid from water. Chem. Eng. Sci. 2018, 331, 64-74. [CrossRef]

36. Li, S.; De Silva, T.; Arsano, I.; Gallaba, D.; Karunanithy, R.; Wasala, M.; Zhang, X.; Sivakumar, P.; Migone, A.; Tsige, M.; et al. High Adsorption of Benzoic Acid on Single Walled Carbon Nanotube Bundles. Sci. Rep. 2020, 10, 10013. [CrossRef] [PubMed]

37. Arsano, I.; Ma, X.; Talapatra, S.; Tsige, M. Adsorption of Benzoic Acid: Structural Organization on the Surfaces of Pristine and Functionalized Single-Walled Carbon Nanotubes. ACS EST Water 2020. [CrossRef] 
38. Behvandi, A.; Safekordi, A.A.; Khorasheh, F. Removal of benzoic acid from industrial wastewater using metal organic frameworks: Equilibrium, kinetic and thermodynamic study. J. Porous Mater. 2017, 24, 165-178. [CrossRef]

39. Policicchio, A.; Vuono, D.; Rugiero, T.; De Luca, P.; Nagy, J.B. Study of MWCNTs adsorption perfomances in gas processes. J. CO2 Util. 2015, 10, 30-39. [CrossRef]

40. Datsyuk, V.; Kalyva, M.; Papagelis, K.; Parthenios, J.; Tasis, D.; Siokou, A.E.; Kallitsis, J.K.; Galiotis, C. Chemical Oxidation of Multi-Walled Carbon Nanotubes. Carbon 2008, 46, 833-840. [CrossRef]

41. Wisniewski, M.; Gauden, P.A.; Terzyk, A.P.; Kowalczyk, P.; Pacholczyk, A.; Furmaniak, S. Detecting adsorption space in carbon nanotubes by benzene uptake. J. Colloid Interface Sci. 2013, 391, 74-85. [CrossRef] [PubMed] 